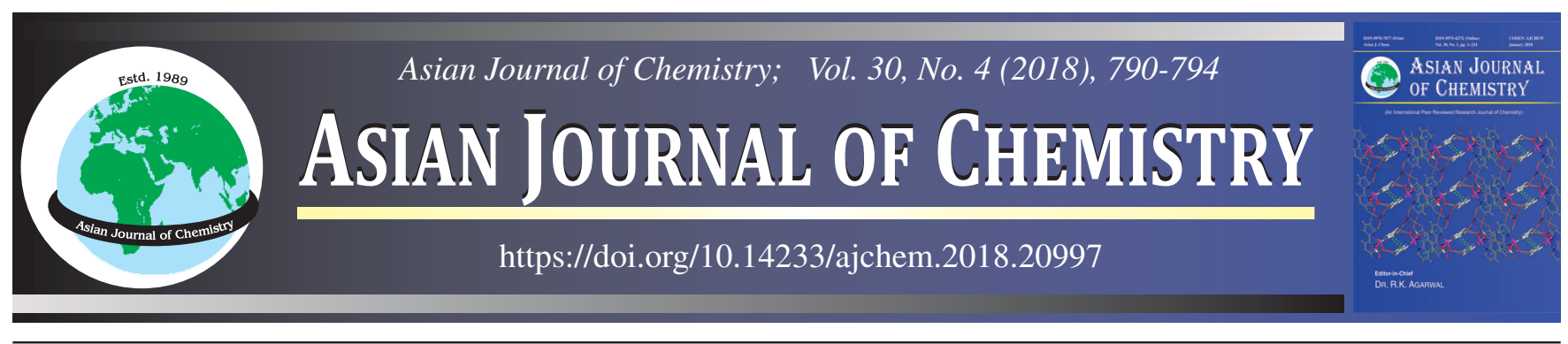

\title{
Analysis of Viscosity-Temperature Behaviour of Karanja Oil Trimethylolpropane Ester Bio-lubricant Base Stock
}

\section{Umesh Chandra Sharma ${ }^{1, *}$, Sadhana Sachan ${ }^{2}$ and Shishir Sinha ${ }^{3}$}

${ }^{1}$ Department of Chemical Engineering, University Institute of Engineering and Technology, Chhatrapati Shahu Ji Maharaj University, Kanpur208 024, India

${ }^{2}$ Department of Chemical Engineering, Motilal Nehru National Institute of Technology, Allahabad-211 004, India

${ }^{3}$ Department of Chemical Engineering, Indian Institute of Technology Roorkee, Roorkee-247 667, India

*Corresponding author: E-mail: uc_sharma@hotmail.com

\begin{abstract}
The work presented deals with the viscous flow characterization of karanja oil based bio-lubricant base stock. Karanja oil trimethylolpropane ester (KOTMPE) bio-lubricant base stock was prepared from karanja oil methyl ester (KOME) and trimethylolpropane (TMP) using acidcatalyzed transesterification synthesis protocol. The viscosities were measured at $10-60{ }^{\circ} \mathrm{C}$ and $10-1000 \mathrm{~s}^{-1}$ shear rates using model $\mathrm{HR}-3$ Discovery Hybrid rheometer. The viscosity-temperature interdependences at different shear rates were modeled using the Arrhenius equation. The viscosity values predicted with Arrhenius model were found in good agreement with measured values. The flow behaviour index of KOTMPE bio-lubricant stretched from 1.036 to 1.527 , which suggested a gradual shift in fluid behaviour from Newtonian to non-Newtonian with increase in temperature. The study confirmed that Arrhenius equation along with Ostwald-deWaele power law could be used to predict the apparent viscosity and flow behaviour of synthesized KOTMPE bio-lubricant oil.
\end{abstract}

Keywords: Karanja oil, Ester, Arrhenius equation, Ostwald-deWaele power law, Flow behaviour index, Activation energy.

\section{INTRODUCTION}

The world annual lubricating oil production stands around 40 million metric tons [1], of which about $50 \%$ is lost to the environment $[2,3]$. In recent years, vegetable oils based biolubricants have emerged as a potential substitute for mineral oil based lubricants on account of their superior environment friendly and lubricity characteristics [4].

Almost all vegetable oils (edible and non-edible) have been worked upon by researchers for application as lubricants with varying degrees of success. These oils may be used without any chemical modification or may be blended with petroleum lube oil base stocks or additives or may be chemically modified via esterification, transesterification, epoxidation and hydrolysis routes. The major vegetable oils analyzed for biolubricant applications include castor oil [5], canola oil [6], soybean oil [7], sunflower oil [8], palm oil [9], Jatropha curcas oil [10], rapeseed oil [11], rubber seed oil [12], etc. Since the edible vegetable oils are more important for human civilization as key source of nutrition, the bio-lubricant research has gradually shifted to non-edible vegetable oils such as karanja, linseed, tobacco, waste cooking oil [13], algae oil and microalgae [14] and animal fats.
Rheology is the study of flow and deformation of material under application of stress [15]. The rheological behaviour of a material is thus a relationship between stress and deformation appropriately represented by a mathematical expression consisting of the necessary variables and a few constants. These constants are characteristic for a given material [16]. In general, the need for rheological study of a material appears from the assumption that measured rheological behaviour may prove of considerable significance to material characterization, quality control, process control and modeling in industrial situations $[17,18]$. The precise knowledge of the rheological properties of karanja oil (KO), karanja oil methyl ester (KOME) and karanja oil trimethylolpropane ester (KOTMPE) is essential in movement of bulk quantities of these oils to have better control over oil velocity, pump pressure and energy requirement in esterification and transesterification process steps [19].

The rheological characteristics of mineral and renewable ecological bio-lubricants have been analyzed at wide ranges of temperature and shear rate parameters by researchers. Arrhenius equation has been applied by most researchers to express the effect of temperature on apparent viscosity of test oils. Sathivel et al. [20] studied the rheological properties of unrefined pollock oil at different temperatures at shear rates varying from 
0 to $500 \mathrm{~s}^{-1}$ using AR2000 rheometer fitted with a cone plate geometry. In similar manner, Huang and Sathivel [19] studied the rheological properties of unpurified salmon oil at 5,10 , $15,20,25,30$ and $35^{\circ} \mathrm{C}$ and shear rates varying from 0 to 500 $\mathrm{s}^{-1}$ using advanced AR2000 TA Instruments rheometer. The temperature and the apparent viscosity of oil were fairly correlated through the given Arrhenius relationship: $\mu=\mathrm{A} \exp \left(\mathrm{E}_{\mathrm{a}} / \mathrm{RT}\right)$. Quinchia et al. [21] studied the low temperature viscous flow behaviour of castor, rapeseed, soybean, sunflower and high oleic sunflower oils blended with viscosity modifier and pour point depressant additives over a temperature range of -40 to $120{ }^{\circ} \mathrm{C}$ at shear rate $10 \mathrm{~s}^{-1}$ in a rotational controlled strain rheometer. The group reported that an Arrhenius type equation represents fairly well the variation of oil viscosity at temperatures usually above $-5^{\circ} \mathrm{C}$. Vasishth et al. [22] studied the viscosity-temperature behaviour of MG 20W-50, SAE 20W-50, MC 20W-50, EP 90 and DXT III industrial lubricants at 20 to $50{ }^{\circ} \mathrm{C}$ temperatures and 10 to $100 \mathrm{~s}^{-1}$ shear rates in an Anton-Paar rheometer. They found that the exponential variations of dynamic viscosities with temperature for all test lubricants obey the Arrhenius equation.

The objectives of the present study were to evaluate the rheological properties of synthesized KOTMPE bio-lubricant basestock and to establish a relationship between apparent viscosity and temperature at different shear rates. In addition, the power law was applied to characterize the flow behaviour index of the synthesized bio-lubricant oil sample at different temperatures.

\section{EXPERIMENTAL}

The feedstock karanja oil was procured from Kanakdhara Agro Industries, Jaipur (India). The average fatty acid composition of karanja oil (average molar mass $886.71 \mathrm{~g} / \mathrm{mol}$ ) was oleic acid $49.4 \%$, linoleic acid $19.0 \%$, palmitic acid $10.6 \%$, stearic acid $6.8 \%$, behenic acid $5.3 \%$, arachidic acid $4.1 \%$, lignoceric acid $2.4 \%$ and rest $2.4 \%$. Trimethylolpropane (TMP) (molar mass $134.17 \mathrm{~g} / \mathrm{mol}$ ) was imported from SigmaAldrich (Germany). Methanol and anhydrous sodium sulphate were obtained from Merck Specialities Pvt. Limited, Mumbai. The catalyst sulphuric acid abt. $98 \%$ LR was purchased from S.D. Fine-Chem Limited, Mumbai. Silicon high vacuum grease, fuller's earth, potassium hydroxide pellets and phenolphthalein indicator solution were supplied by local chemical supplier. All reagents were used without any purification.

In the reaction scheme, first, the intermediate karanja oil methyl ester (KOME) biodiesel was synthesized from the feedstock karanja oil and then final product karanja oil trimethylolpropane ester (KOTMPE) bio-lubricant basestock was formed. The experimental set-up for the first part of the reaction scheme consisted of a batch type three-necked, $2 \mathrm{~L}$ round bottom glass flask. The centre neck was equipped with a reflux condenser to reflux the alcohol vapours back to the flask to prevent any reactant loss. The water to reflux condenser was supplied from an external low temperature water bath. The reflux condenser was also useful in maintaining the atmospheric pressure inside the flask [23]. One side neck was equipped with a thermal sensor to keep a continuous watch over reaction temperature. The other side neck was used as a sampling port.
REMI 2RML heater cum magnetic stirrer was used for heating cum mixing of reactant mass. PTFE coated magnetic stirrer bar was rotated at $600 \mathrm{rpm}$ to overcome the mass transfer limitation of slow reaction rate [14]. A custom-made temperature controller, able to control the temperature within $\pm 0.1^{\circ} \mathrm{C}$ of the set value, was used to maintain the reaction temperature. The set-up for the next part of the reaction scheme required connection of the condenser to a vacuum line equipped with relief valve, accumulator and a vacuum trap.

Synthesis of karanja oil methyl ester: A two-step esterification/transesterification process (acid-catalyzed esterification followed by alkali-catalyzed transesterification) was used on account of free fatty acid content in karanja oil exceeding the barrier of $0.5-1 \%$ [24].

Acid-catalyzed esterification: $0.5 \mathrm{~mol}$ of karanja oil, 3 mol of methanol and $1 \% \mathrm{H}_{2} \mathrm{SO}_{4}$ (w/w karanja oil) were taken as reaction ingredients. The reaction was carried out at $65^{\circ} \mathrm{C}$ for a period of $5 \mathrm{~h}$ with continuous stirring at $600 \mathrm{rpm}$. After the completion of the reaction, the reaction mixture was transferred to a separating funnel and allowed to settle overnight under influence of gravity. The water rich top layer was discarded and the lower ester layer was washed with equal volumes of warm water until the discarded rinse water reached a $\mathrm{pH}$ level of 6-7. The ester obtained was then dried over anhydrous sodium sulphate and analyzed for its acid and saponification values.

Base-catalyzed transesterification: The prerequisite for base-catalyzed transesterification is an acid value of feed material equal to or less than $2 \mathrm{mg} \mathrm{KOH} / \mathrm{g}$ oil. The reaction conditions were similar to previous step except for replacement of acid catalyst with base catalyst. $0.5 \mathrm{~mol}$ of pretreated oil was transferred into three-necked flask and heated to reaction temperature. $1.25 \% \mathrm{KOH} \mathrm{(w/w} \mathrm{pretreated} \mathrm{oil)} \mathrm{was} \mathrm{dissolved}$ in $3 \mathrm{~mol}$ of methanol in a separate beaker and the resulting solution was added to the content of the flask at reaction temperature. The time of reaction was counted from the moment when all the reaction ingredients were added to the flask and the reaction temperature was achieved. After the scheduled period, the reaction mixture was allowed to settle for 8-10 $\mathrm{h}$ in a separating funnel by gravity. Two distinct layers were formed due to differences in their density and polarity. The upper layer consisted of KOME, methanol and some soap. The bottom layer consisting glycerol, excess methanol, catalyst, impurities and remains of unreacted oil was separated. The methyl ester layer was then washed with warm water three to four times to remove soaps, salts, free fatty acids, catalyst, glycerol or methanol residuals and dried over anhydrous sodium sulphate. The washing was repeated until the discarded rinse water reached a $\mathrm{pH}$ level of 6-7 and no soap bubbles appeared. A clear amber yellow methyl ester was formed.

Synthesis of karanja oil trimethylolpropane ester: Transesterification of KOME with TMP was carried out to obtain KOTMPE bio-lubricant basestock. The following reaction conditions were applied: molar ratio of KOME to TMP 4:1, $\mathrm{H}_{2} \mathrm{SO}_{4}$ catalyst $2 \%$ (w/w) based on weight of methyl ester, temperature $150{ }^{\circ} \mathrm{C}$, reaction time $3 \mathrm{~h}$ and rate of stirring 600 rpm. $0.5 \mathrm{~mol}$ of KOME were heated in a three-necked flask to $65^{\circ} \mathrm{C}$. At this temperature $0.125 \mathrm{~mol}$ of crystalline TMP were 
poured in to the flask. The contents of the flask were continuously stirred to provide uniform mixing and encourage melting of TMP. Now the temperature was set at $150{ }^{\circ} \mathrm{C}$. At $120{ }^{\circ} \mathrm{C}$ $\mathrm{H}_{2} \mathrm{SO}_{4}$ was added to the reaction mixture and reaction was timed from this point onwards. A vacuum of $10 \mathrm{mbar}$ was applied to avoid spillover reaction [25]. The pressure was maintained till the end of the reaction. The methanol produced in the system was continuously withdrawn to enhance the forward reaction and increase methyl ester conversion due to reversible nature of the reaction. The reaction mixture was cooled to ambient temperature upon completion and vacuum filtered to remove the solid materials formed during the reaction. The resulting TMP ester was washed repeatedly with warm water until it was acid free and then dried over a hot plate.

Measurement of viscosity and shear stress with temperature at varying shear rates: The viscosity analyses for biolubricant sample were done as a function of temperature range from 10 to $60^{\circ} \mathrm{C}$ at constant shear rate of 10,100 and $1000 \mathrm{~s}^{-1}$. Eleven data points with an interval of $5{ }^{\circ} \mathrm{C}$ were selected for analytical purpose. The determination of shear stress corresponding to a shear rate is not difficult [15] and is obtained by multiplying the viscosity with shear rate according to the following relation [26]:

$$
\tau=\mu \gamma
$$

The measured values of viscosity and shear stress with temperature at three different shear rates are reported in Table-1.

The effect of temperature on apparent viscosity of the synthesized bio-lubricant sample was articulated by the Arrhenius equation applied in following form:

$$
\mu=\mathrm{A} \exp \left(\mathrm{E}_{\mathrm{a}} / \mathrm{RT}\right)
$$

A plot of $\ln$ (apparent viscosity) versus $1 /$ (absolute temperature) was constructed for test sample at each shear rate. As the cold flow behaviour of bio-lubricant sample was quite different from that at higher temperatures, separate plots were drawn for temperature ranges $10-20^{\circ} \mathrm{C}$ and $20-60^{\circ} \mathrm{C}$. A best fit trend line was drawn by connecting the actual data points. Then the slope, intercept and regression coefficient were calculated using this trend line. The magnitude of $E_{a}$ was calculated by multiplying the slope of the straight line to the gas constant $\mathrm{R}$ and A was an exponential of the intercept [20]. The activation energy represents a sort of energy barrier that should be overpowered for an elementary flow process to proceed [15]. The frequency factor is a temperature independent quantity. The viscosity values of the bio-lubricant sample were predicted using the Arrhenius equation (eqn. 2) at 10, 20, 30, 40, 50 and $60{ }^{\circ} \mathrm{C}$ and shear rate variation of 10,100 and $1000 \mathrm{~s}^{-1}$.

Measurement of viscosity and shear stress with shear rate at varying temperatures - The viscosity measurements were carried out at three different temperatures (27, 60 and 90 ${ }^{\circ} \mathrm{C}$ ) in a shear rate range of 100 to $1000 \mathrm{~s}^{-1}$. Nineteen measure points each at an equal interval of 50 rotations per second (rps) were taken with regard to shear rate variation. The shear stress measurements were made following the method described earlier. The values of viscosity and shear stress with shear rate at three different temperatures are reported in Table-2.

Ostwald-deWaele power law model given in eqn. 3 was used to analyze the flow behaviour index of the synthesized bio-lubricating oil basestock at 27,60 and $90{ }^{\circ} \mathrm{C}$.

$$
\tau=\mathrm{K} \gamma^{\mathrm{n}}
$$

The logarithms were taken on both sides of eqn. 3 and $\log \tau$ versus $\log \gamma$ plots were constructed for each temperature value. The intercept of the resulting straight line provided the magnitude of $\log \mathrm{K}$ and the slope of the line gave $\mathrm{n}$ [19]. Both the consistency index and flow behaviour index are significant fluid properties and are considered constant at a given temperature. The power law classifies the fluids into three different categories based on their flow behaviour index: newtonian $(\mathrm{n}=1)$, pseudoplastic $(\mathrm{n}<1)$ and dilatant $(\mathrm{n}>1)$ [27]. The shear stress values of the synthesized bio-lubricant sample were predicted using power law model (eqn. 3 ) at shear rate variation of $100,250,500,750$ and $1000 \mathrm{~s}^{-1}$ and temperatures of 27,60 and $90{ }^{\circ} \mathrm{C}$.

\section{RESULTS AND DISCUSSION}

Figs. 1 and 2 represent Arrhenius plots for apparent viscosity of the synthesized bio-lubricant sample in temperature ranges of $10-20{ }^{\circ} \mathrm{C}$ and $20-60^{\circ} \mathrm{C}$, respectively. The Arrhenius equation was applied to calculate the magnitude of activation energy and frequency factor of the test sample from the trend lines of these plots. The Arrhenius equation parameters obtained from two plots are collected in Table-3. The predicted viscosity values agreed well with the measured viscosity values as evident from Table-4. The high magnitude of $\mathrm{R}^{2}$ value indicated that changes in apparent viscosity of synthesized biolubricating oil with temperature could be modeled suitably using the Arrhenius equation. The study further confirmed the

\begin{tabular}{|c|c|c|c|c|c|c|}
\hline \multirow{2}{*}{ Temp. $\left({ }^{\circ} \mathrm{C}\right)$} & \multicolumn{3}{|c|}{ Viscosity (Pa.s) } & \multicolumn{3}{|c|}{ Shear stress $(\mathrm{Pa})$} \\
\hline & Shear rate $10 / \mathrm{s}$ & Shear rate $100 / \mathrm{s}$ & Shear rate $1000 / \mathrm{s}$ & Shear rate $10 / \mathrm{s}$ & Shear rate $100 / \mathrm{s}$ & Shear rate $1000 / \mathrm{s}$ \\
\hline 10 & 2.821 & 0.885 & 0.149 & 28.208 & 88.495 & 149.381 \\
\hline 15 & 0.524 & 0.124 & 0.053 & 5.242 & 12.372 & 52.954 \\
\hline 20 & 0.035 & 0.032 & 0.032 & 0.354 & 3.220 & 31.618 \\
\hline 25 & 0.027 & 0.026 & 0.026 & 0.268 & 2.608 & 26.081 \\
\hline 30 & 0.022 & 0.022 & 0.022 & 0.223 & 2.186 & 21.839 \\
\hline 35 & 0.019 & 0.019 & 0.019 & 0.188 & 1.858 & 18.602 \\
\hline 40 & 0.016 & 0.016 & 0.016 & 0.162 & 1.595 & 16.029 \\
\hline 45 & 0.014 & 0.014 & 0.014 & 0.141 & 1.389 & 13.938 \\
\hline 50 & 0.012 & 0.012 & 0.012 & 0.124 & 1.222 & 12.248 \\
\hline 55 & 0.012 & 0.011 & 0.011 & 0.115 & 1.084 & 10.857 \\
\hline 60 & 0.012 & 0.011 & 0.010 & 0.120 & 1.050 & 9.897 \\
\hline
\end{tabular}

TABLE-1

VISCOSITY AND SHEAR STRESS versus TEMPERATURE MEASUREMENTS AT DIFFERENT SHEAR RATES 


\begin{tabular}{|c|c|c|c|c|c|c|}
\hline \multicolumn{7}{|c|}{$\begin{array}{c}\text { TABLE-2 } \\
\text { VISCOSITY AND SHEAR STRESS versus SHEAR RATE MEA }\end{array}$} \\
\hline \multirow{2}{*}{ Shear rate $(1 / s)$} & \multicolumn{3}{|c|}{ Viscosity $(\mathrm{Pa} \cdot \mathrm{s})$} & \multicolumn{3}{|c|}{ Shear stress $(\mathrm{Pa})$} \\
\hline & $27^{\circ} \mathrm{C}$ & $60^{\circ} \mathrm{C}$ & $90^{\circ} \mathrm{C}$ & $27^{\circ} \mathrm{C}$ & $60^{\circ} \mathrm{C}$ & $90^{\circ} \mathrm{C}$ \\
\hline 100 & 0.0244 & 0.01050 & 0.00314 & 2.44 & 1.05 & 0.31 \\
\hline 150 & 0.0242 & 0.01046 & 0.00332 & 3.63 & 1.57 & 0.50 \\
\hline 200 & 0.0251 & 0.01136 & 0.00380 & 5.02 & 2.27 & 0.76 \\
\hline 250 & 0.0252 & 0.01148 & 0.00518 & 6.30 & 2.87 & 1.30 \\
\hline 300 & 0.0248 & 0.01084 & 0.00576 & 7.44 & 3.25 & 1.73 \\
\hline 350 & 0.0248 & 0.01049 & 0.00561 & 8.68 & 3.67 & 1.96 \\
\hline 400 & 0.0248 & 0.01068 & 0.00571 & 9.92 & 4.27 & 2.28 \\
\hline 450 & 0.0250 & 0.01150 & 0.00617 & 11.25 & 5.18 & 2.78 \\
\hline 500 & 0.0252 & 0.01227 & 0.00668 & 12.60 & 6.14 & 3.34 \\
\hline 550 & 0.0253 & 0.01286 & 0.00713 & 13.92 & 7.07 & 3.92 \\
\hline 600 & 0.0254 & 0.01353 & 0.00757 & 15.24 & 8.12 & 4.54 \\
\hline 650 & 0.0256 & 0.01395 & 0.00796 & 16.64 & 9.07 & 5.17 \\
\hline 700 & 0.0257 & 0.01445 & 0.00820 & 17.99 & 10.12 & 5.74 \\
\hline 750 & 0.0259 & 0.01525 & 0.00837 & 19.43 & 11.44 & 6.28 \\
\hline 800 & 0.0260 & 0.01575 & 0.00876 & 20.80 & 12.60 & 7.01 \\
\hline 850 & 0.0262 & 0.01635 & 0.00904 & 22.27 & 13.90 & 7.68 \\
\hline 900 & 0.0263 & 0.01695 & 0.00925 & 23.67 & 15.26 & 8.33 \\
\hline 950 & 0.0264 & 0.01745 & 0.00961 & 25.08 & 16.58 & 9.13 \\
\hline 1000 & 0.0266 & 0.01785 & 0.00990 & 26.60 & 17.85 & 9.90 \\
\hline
\end{tabular}

\section{TABLE-3}

ARRHENIUS PARAMETERS FOR SYNTHESIZED BIO-LUBRICANT OIL

\begin{tabular}{cccc|ccc}
\hline \multirow{2}{*}{$\gamma(1 / \mathrm{s})$} & $\mathrm{A}(\mathrm{Pa} . \mathrm{s})$ & $\mathrm{E}_{\mathrm{a}}(\mathrm{J} / \mathrm{mol})$ & $\mathrm{R}^{2}$ & $\mathrm{c}$ A (Pa.s) & $\mathrm{E}_{\mathrm{a}}(\mathrm{J} / \mathrm{mol})$ & $\mathrm{R}^{2}$ \\
\cline { 2 - 7 } & $4.05 \times 10^{-56}$ & $303,242.06$ & 0.9651 & $2.82 \times 10^{-6}$ & $22,706.42$ & 0.9453 \\
$10 / \mathrm{s}$ & $3.71 \times 10^{-43}$ & $229,577.95$ & 0.9768 & $2.17 \times 10^{-6}$ & $23,274.68$ & 0.9857 \\
$100 / \mathrm{s}$ & $1.99 \times 10^{-21}$ & $107,581.77$ & 0.9276 & $1.86 \times 10^{-6}$ & $23,653.21$ & 0.9949 \\
$1000 / \mathrm{s}$ & & & &
\end{tabular}

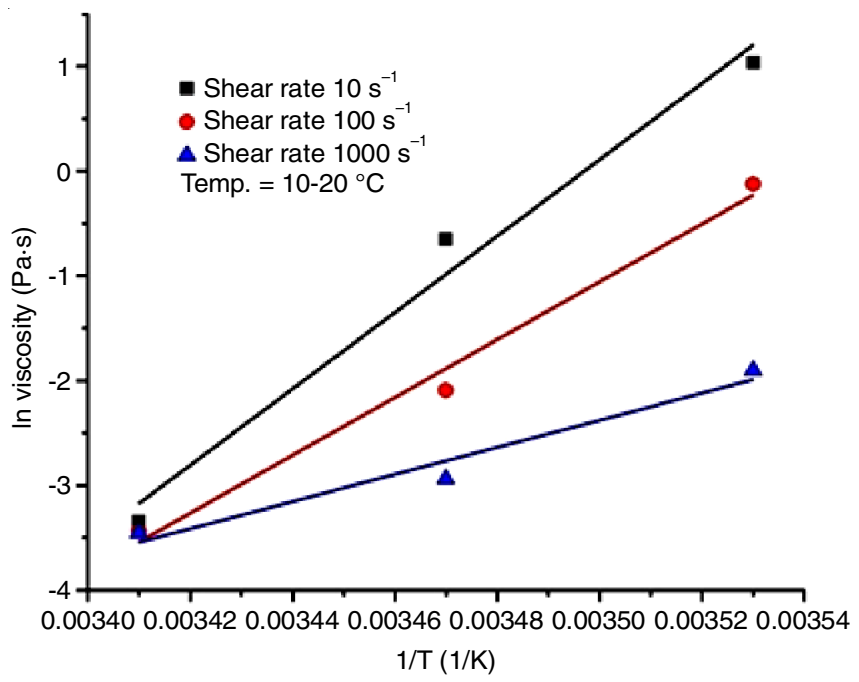

Fig. 1. Arrhenius plot for apparent viscosity of bio-lubricant oil in temperature range of $10-20{ }^{\circ} \mathrm{C}$

TABLE-4 MEASURED AND PREDICTED (IN PARENTHESIS) VISCOSITY DATA (Pa.s) AT DIFFERENT SHEAR RATES

\begin{tabular}{cccc}
\hline Temp. $\left({ }^{\circ} \mathrm{C}\right)$ & $\begin{array}{c}\text { Shear rate } \\
10 / \mathrm{s}\end{array}$ & $\begin{array}{c}\text { Shear rate } \\
100 / \mathrm{s}\end{array}$ & $\begin{array}{c}\text { Shear rate } \\
1000 / \mathrm{s}\end{array}$ \\
\hline 10 & $2.821(3.804)$ & $0.885(0.881)$ & $0.149(0.143)$ \\
20 & $0.035(0.047)$ & $0.032(0.032)$ & $0.032(0.030)$ \\
20 & $0.035(0.032)$ & $0.032(0.031)$ & $0.032(0.031)$ \\
30 & $0.022(0.023)$ & $0.022(0.022)$ & $0.022(0.022)$ \\
40 & $0.016(0.017)$ & $0.016(0.017)$ & $0.016(0.016)$ \\
50 & $0.012(0.013)$ & $0.012(0.013)$ & $0.012(0.012)$ \\
60 & $0.012(0.010)$ & $0.011(0.010)$ & $0.010(0.010)$ \\
\hline
\end{tabular}

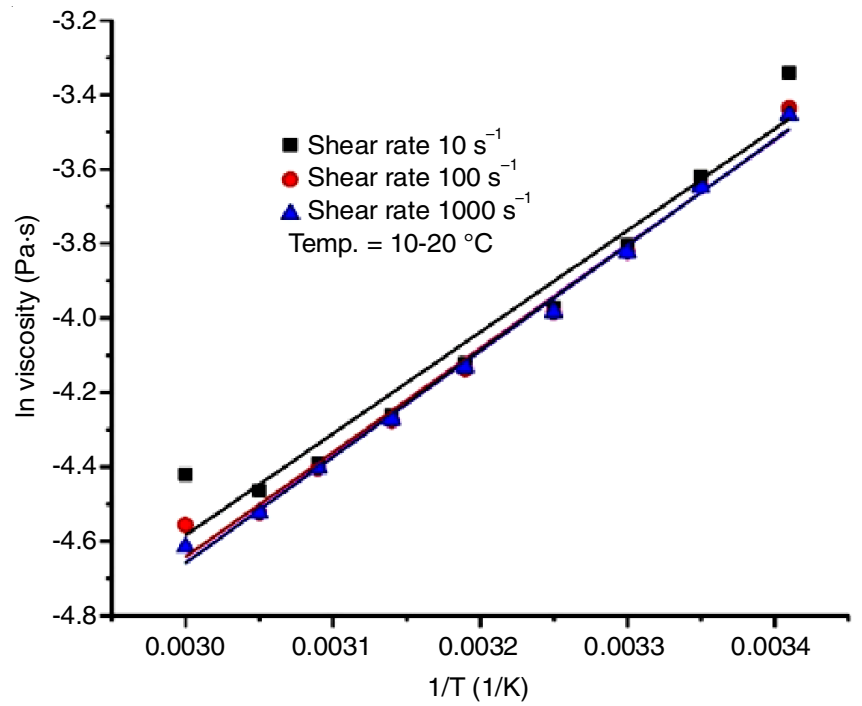

Fig. 2. Arrhenius plot for apparent viscosity of bio-lubricant oil in temperature range of $20-60{ }^{\circ} \mathrm{C}$

observation that the viscosity of the synthesized bio-lubricating oil was largely influenced by temperature. However, this effect was more pronounced at low temperature and was moderate at high temperatures.

Fig. 3 characterizes the power law behaviour of synthesized bio-lubricant sample at 27,60 and $90^{\circ} \mathrm{C}$. The power law parameters for the sample are given in Table-5. The flow behaviour index (n) of the bio-lubricant sample ranged from 1.036 to 1.527 , which indicated Newtonian fluid behaviour at room temperature that gradually transformed to non-Newtonian 


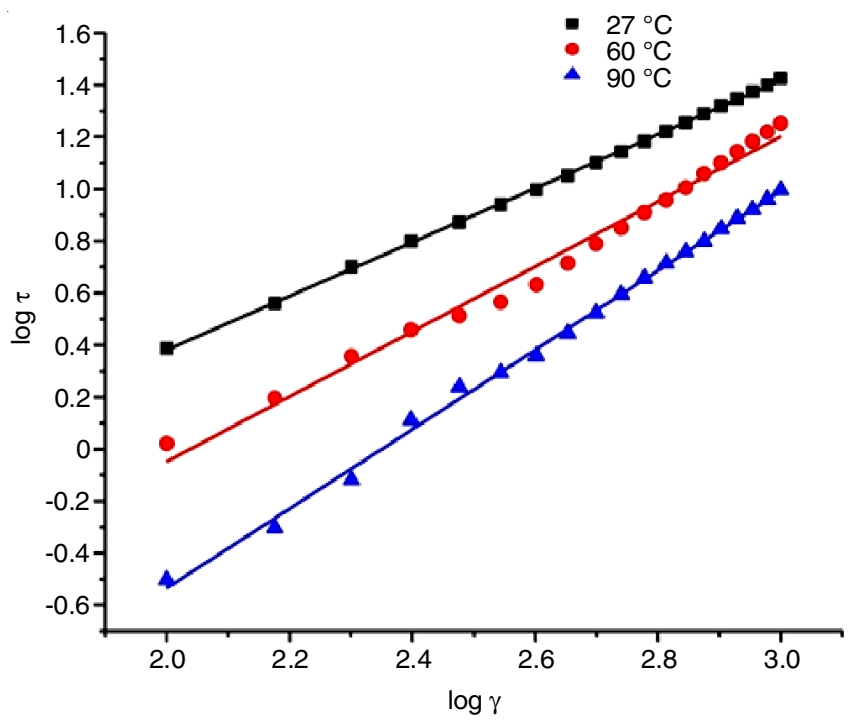

Fig. 3. Power law plot for bio-lubricant oil at 27,60 and $90{ }^{\circ} \mathrm{C}$

\begin{tabular}{cccc}
\multicolumn{4}{c}{ TABLE-5 } \\
& POWER LAW PARAMETERS \\
\hline Temp. $\left({ }^{\circ} \mathrm{C}\right)$ & $\mathrm{n}$ & $\mathrm{K}$ & $\mathrm{R}^{2}$ \\
\hline 27 & 1.036 & $20.32 \times 10^{-3}$ & 0.999 \\
60 & 1.250 & $2.83 \times 10^{-3}$ & 0.986 \\
90 & 1.527 & $0.26 \times 10^{-3}$ & 0.997 \\
\hline
\end{tabular}

behaviour with increase in temperature. The consistency index (K) for the sample was higher at lower temperatures. Little less than elevenfold increase in the magnitude of the $\mathrm{K}$ values between 90 and $60{ }^{\circ} \mathrm{C}$ was observed, whereas more than sevenfold increase between 60 and $27{ }^{\circ} \mathrm{C}$ was observed. Table- 6 displays a good harmony between the experimental and the predicted shear stress values.

TABLE-6

EXPERIMENTAL AND PREDICTED (IN PARENTHESIS) SHEAR STRESS VALUES (Pa) AT DIFFERENT TEMPERATURES

\begin{tabular}{cccc}
\hline Shear rate $(1 / \mathrm{s})$ & $\mathrm{T}=27^{\circ} \mathrm{C}$ & $\mathrm{T}=60{ }^{\circ} \mathrm{C}$ & $\mathrm{T}=90{ }^{\circ} \mathrm{C}$ \\
\hline 100 & $2.44(2.40)$ & $1.05(0.89)$ & $0.31(0.29)$ \\
250 & $6.30(6.20)$ & $2.87(2.81)$ & $1.30(1.19)$ \\
500 & $12.60(12.71)$ & $6.14(6.69)$ & $3.34(3.44)$ \\
750 & $19.43(19.34)$ & $11.44(11.11)$ & $6.28(6.39)$ \\
1000 & $26.60(26.06)$ & $17.85(15.91)$ & $9.90(9.91)$ \\
\hline
\end{tabular}

\section{Conclusion}

This study characterized the flow behaviour of synthesized karanja oil trimethylolpropane ester (KOTMPE) bio-lubricant basestock. The test sample was analyzed for its viscosity in temperature range of $10-60{ }^{\circ} \mathrm{C}$ at shear rates of 10,100 and $1000 \mathrm{~s}^{-1}$. These data were then fitted in Arrhenius equation and Ostwald-deWaele power law model for flow characterization. The Arrhenius equation provided information on activation energy of the test sample. Karanja oil trimethylolpropane ester bio-lubricant was characterized having high activation energies at low temperatures and low shear rates. The viscosity values predicted with Arrhenius equation agreed substantially with experimental values to establish fitness of Arrhenius parameters. The power law model characterized the KOTMPE biolubricant as near Newtonian at room temperature and non-
Newtonian dilatant fluid at high temperatures. The study validated the application of Arrhenius model to predict the apparent viscosity of synthesized KOTMPE bio-lubricant basestock at different temperatures and shear rates as well.

\section{REFERENCES}

1. A. Feiferyte, J. Dvarioniene and M. Gumbyte, J. Clean. Prod., 95, 281 (2015); https://doi.org/10.1016/j.jclepro.2015.02.044.

2. B.J. Bremmer, L. Plonsker and J. Martin, Bio-Based Lubricants: A Market Opportunity Study Update, United Soybean Board, Omitech International Limited, Midland, MI, USA (2013).

3. M. Ramezani and S.R. Schmid, J. Manuf. Process., 19, 112 (2015); https://doi.org/10.1016/j.jmapro.2015.06.008.

4. K.V. Padmaja, B.V.S.K. Rao, R.K. Reddy, P.S. Bhaskar, A.K. Singh and R.B.N. Prasad, Ind. Crops Prod., 35, 237 (2012); https://doi.org/10.1016/j.indcrop.2011.07.005.

5. M. Hajar and F. Vahabzadeh, Ind. Crops Prod., 52, 430 (2014); https://doi.org/10.1016/j.indcrop.2013.11.020.

6. P.K. Sripada, R.V. Sharma and A.K. Dalai, Ind. Crops Prod., 50, 95 (2013); https://doi.org/10.1016/j.indcrop.2013.07.018.

7. A. Adhvaryu and S.Z. Erhan, Ind. Crops Prod., 15, 247 (2002); https://doi.org/10.1016/S0926-6690(01)00120-0.

8. L. Lazzeri, M. Mazzoncini, A. Rossi, E. Balducci, G. Bartolini, L. Giovannelli, R. Pedriali, R. Petroselli, G. Patalano, G. Agnoletti, A. Borgioli, B. Croce and L. D'Avino, Ind. Crops Prod., 24, 280 (2006); https://doi.org/10.1016/j.indcrop.2006.06.017.

9. N.A.M. Aziz, R. Yunus, U. Rashid and A.M. Syam, Ind. Crops Prod., 62, 305 (2014); https://doi.org/10.1016/j.indcrop.2014.08.040.

10. N.H. Arbain and J. Salimon, J. Sci. Technol., 2, 47 (2010).

11. E. Kleinaite, V. Jaska, B. Tvaska and I. Matijosyte, J. Clean. Prod., 75, 40 (2014);

https://doi.org/10.1016/j.jclepro.2014.03.077.

12. A. Aravind, M.L. Joy and K.P. Nair, Ind. Crops Prod., 74, 14 (2015); https://doi.org/10.1016/j.indcrop.2015.04.014.

13. W. Li and X. Wang, J. Oleo Sci., 64, 367 (2015); https://doi.org/10.5650/jos.ess14235.

14. A. Talebian-Kiakalaieh, N.A.S. Amin and H. Mazaheri, Appl. Energy, 104, 683 (2013); https://doi.org/10.1016/j.apenergy.2012.11.061.

15. M.A. Rao, Rheology of Fluids and Semisolid Foods: Principles and Applications, Aspen Publishers, Gaithersburg, MD (1999).

16. A.Y. Malkin, Rheology Fundamentals, ChemTec Publishing, Ontario (1994).

17. H.A. Barnes, J.F. Hutton and K. Walters, An Introduction to Rheology, Elsevier Science Publishers, Amsterdam (1993).

18. C.W. Macosko, Rheology Principles, Measurements And Applications, Wiley-VCH, New York (1994).

19. J. Huang and S. Sathivel, J. Food Eng., 89, 105 (2008); https://doi.org/10.1016/j.jfoodeng.2008.03.007.

20. S. Sathivel, J. Huang and W. Prinyawiwatkul, J. Food Eng., 84, 187 (2008); https://doi.org/10.1016/j.jfoodeng.2007.04.027.

21. L.A. Quinchia, M.A. Delgado, J.M. Franco, H.A. Spikes and C. Gallegos, Ind. Crops Prod., 37, 383 (2012);

https://doi.org/10.1016/j.indcrop.2011.12.021.

22. A. Vasishth, P. Kuchhal and G. Anand, Conference Papers in Science, 2014, 1 (2014); https://doi.org/10.1155/2014/324615.

23. Vivek and A.K. Gupta, J. Sci. Ind. Res., 63, 39 (2004).

24. M. Berrios, J. Siles, M.A. Martin and A. Martin, Fuel, 86, 2383 (2007); https://doi.org/10.1016/j.fuel.2007.02.002.

25. M.F.M. Gunam Resul, T.I. Mohd. Ghazi and A. Idris, Ind. Crops Prod., 38, 87 (2012);

https://doi.org/10.1016/j.indcrop.2012.01.012.

26. S. Tanveer, U.C. Sharma and R. Prasad, Indian J. Chem. Technol., 13, 180 (2006).

27. C.J. Geankoplis, Transport Processes and Unit Operations, Allyn and Bacon, Inc., Massachusetts (1978). 